\title{
Manifestations of Culture in Website Design
}

\author{
Inhwa Kim and Jasna Kuljis \\ People and Interactivity Research Centre, School of Information Systems, Computing and Mathematics, \\ Brunel University, West London, Uxbridge, United Kingdom
}

\begin{abstract}
The web is a global phenomenon and its reach and influence ignores political and cultural boundaries. However the web's global presence and easy accessibility does not also mean there are no issues related to the understanding and interpretations of its content. Of particular interest to us is to find out whether there is any effect of culture on web design. In this paper, we report on our research into the identification of elements that can be attributed to culture on website design. We examined and compared South Korean and UK's charity websites and identified these elements of the websites. The findings suggest that there are some differences and preferences in the website design that are mostly related to whether the websites employ multimedia and provide facilities for user input.
\end{abstract}

Keywords: culture, website design

\section{Introduction}

Over the last decade the number of Internet users has been growing exponentially and web has become an important and indispensable communication channel throughout the world. The estimated number of Internet users for September 2009 was 1,733 million of which $27.6 \%$ were English speaking, $22.1 \%$ Chinese, and 7.9\% Spanish [1]. Even though English is still the primary language, the non-Englishspeaking Internet users have increased dramatically. For instance, the number of Arabic and Chinese speaking users has grown 1,907.9\% and $1,087.7 \%$ respectively in the period 2000 2009 compared to English speaking users which increased by $237.0 \%$ during the same period [1]. These statistics clearly suggest that non-English speaking users have an increasingly significant impact on the very nature of the web and the web is now a truly global phenomenon. Since the web connects various geographical regions and people across the world, the need to effectively communicate and understand when using the web as the communication medium is becoming increasingly important. In the research being reported on in this paper, we consider whether cultural differences might present a potential impediment to this medium of communication.

We focus our investigation on differences in the design of web pages that originated in different societies. Because people from different societies / cultures often have different beliefs, attitudes, and values, misunderstandings that may occur in interactions between people of the same culture, may be magnified by the wider differences in intercultural interaction [2]. In addition, understanding cultural issues in web interface designs, if they exist, is vital in order to represent information appropriately to the target users as well as to make sites appealing and attractive. The question we considered was whether the design of the website reflects the culture which it comes from. Similarly, we wanted to assess whether any observed differences are culturally related. Therefore, the aim of this study was to investigate the differences one can observe on websites in different cultures. In order to relate our research into the real world we performed an empirical study of cross national design features for the charity websites of South Korea (hereafter SK) and UK.

\section{Manifestations of Culture}

It is difficult to define a culture and there is no agreement to a specific definition of culture. Anthropologists traditionally have de- 
scribed culture as a group of people having certain aspects of life in common [3]. Hofstede [4] defines culture as "the collective mental programming", which is generally determined by the shared values of their local community context over enduring time. This definition suggests that people from any one group will be formed by mostly the same values and norms as their compatriots. Feather [5] argues that culture provides a wide range of guidelines that are eligible to behaviour in specific circumstances and according to Tse et al. [6] strongly influences our motivations, lifestyles and product selection. According to D'Andrade [7] cultural schemas are developed and shared within the environment we live in, and through this we categorise, process and interpret culturally adapted communication. The result of studies by Hall and Hall [2] and Hofstede [8] provide evidence that cultural value orientations vary significantly across cultures and countries.

Hofstede's cultural dimensions [4] is one of the models, if not the model, most extensively quoted by many researchers in cultural studies. Hofstede's model includes four dimensions:

- Power distance (inequality of power distribution in social hierarchies);

- Individualism vs. Collectivism (the degree to which individuals are integrated into groups)

- Masculinity vs. Femininity (the relative value of gender role, material success versus quality of life and assertive versus modest behaviours);

- Uncertainty avoidance (the extent to which people tolerate ambiguity or feel threatened by uncertain or unknown situations).

We chose SK and UK for our study since, according to Hofstede's model, SK and UK are culturally very different as will be elaborated in more detail in Section 4.

\section{Cultural Implications in the Design of Websites}

Early web interface studies on cultural effects focused on the visible level of culture such as colours, symbols and layout [9]. Web page design elements that may be culturally or genre specific are identified and consequently already have influence on web page design and usability. A specific "cultural marker" signifies a cultural association and denotes a conventionalised use of the feature in the website. Such cultural association can be seen in the frequent use of cultural markers such as national symbols, colour, or spatial organisation in web site design [9-11]. Layout and menu design were considered as central factors of information retrieval system by $\mathrm{Yu}$ and Roh [12]. Marcus and Gould found that the layout of Siemens website from Germany emphasises clear functional design aimed at accomplishing goals quickly [13].

More researchers have started looking into how users from different cultures differ in their perception, attitudes and behaviour towards websites $[14,15]$ and several papers have reported differences in online behaviour across cultures. For example, Asia countries such as Hong Kong appear to prefer using the Internet for social communication and hobby activities whereas the United States tend to use Internet more for product information, search purposes, and e-commerce [15]. Studies that have explored issues of website interactivity, navigation and their perception by international consumers have ; reported that users from different countries have different preferences on web features, navigation, security and product information $[16,17]$. In contrast, some research findings suggested that web based communication is neither fully neutral nor specific to culture [18] or even that the Internet is a global medium which goes beyond the borders of country or culture, delivering information to potential consumers worldwide [19]. Although there is a wealth of research that focuses on cultural influences on website design, the outcomes do not indicate whether a global internet culture exists or a variety of cultural adaptations [20]. In addition, most studies have been carried out with regards to the websites of profit-making organisations such as corporate, B2C, e-commerce websites $[21,22]$. None of them have investigated how cultural values are manifested on the non-profit organisations' websites. That is why we chose to investigate charity websites, a subset of websites from the non-profit organisations. 


\section{Empirical Study Comparing South Korean and UK's Charity Websites}

In this study we examined 40 charity websites from two nations, 20 websites from SK and 20 websites from UK. 'Nations' or countries were chosen as the basis to classify culture since so many and varied researchers have used nation as a categorisation for culture $[2,8,23]$. The reason why South Korea and United Kingdom were the countries (i.e., cultures) used in the study is because they both represent very different cultural values as determined by Hofstede [8] as shown in Table 1. Additional support comes from the extensive study by Nisbett [24] who argued that the thought processes of East Asians tend to be more holistic. They are also inclined to find the 'middle way' between opposing propositions. Westerners, however, are found to be more analytic, categorised and using logical rules [24]. Therefore, we expect that such cultural dimensions give us confidence that these differences will be reflected in both countries' websites, i.e., a high use of community related functions for a 'collectivist' country (SK) and little use of these in an 'individualist' country (UK).

\begin{tabular}{|l|c|c|}
\hline \multirow{2}{*}{ Cultural dimension } & \multicolumn{2}{|c|}{ Nation } \\
\cline { 2 - 3 } & SK & UK \\
\hline \hline Power distance & High & Low \\
\hline Individualism & Low & High \\
\hline Masculinity & Low & High \\
\hline Uncertainty avoidance & High & Low \\
\hline
\end{tabular}

Table 1. Cultural dimensions for SK and UK (adopted from Hofstede [8]).

We focused on one category, the homepages of charity websites (non-profit organisation websites), defined as the first screen seen on the site. If the websites cover a similar topic or purpose, then one can expect that the websites would have more homogeneity in their content, but not necessarily in the organisation and presentation of that content that may be more culturally affected $[16,25]$. Charity websites were chosen on the assumption that they would more likely manifest features and characteristics of the local culture in order to attract local visitors, leading to their enthusiastic support and better fundraising performance. In addition, it is thought that local websites from each nation are designed by local designers who have the cognitive style that is influenced by the national cultural cognitive processes [26].

\section{Methodology}

Each of the selected charity websites from SK and UK were examined in terms of five design categories, namely information, visual design, page layout, user input and multimedia. Further details of each category and the features that were examined are as follows.

1. Information about the organisation, including related laws/regulations, direct donation availability, donation usage details, annual report, press release/publications, staff information, job opening, volunteer demand, donators' list, last update indicator, text only version.

2. Visual design comprises the choice of colour for homepage background, frame, image, hyperlink, logo, text, and the usage of image such as photo and symbol, and navigation.

3. Page layout includes the type of menu, the position of elements such as main menu, sub menu, logo, image, animation, search engine, navigation button, donation menu, sitemap, and the number of images.

4. User input consists of message board, online community, sign in access, online poll, email and location address.

5. Multimedia includes the use of sound, animation and video.

The frequencies of occurrence were counted and categorised. Each of these was observed to determine whether there is any evidence of cultural differences and preferences in terms of design features among the chosen websites.

\section{Results}

Both sets of sites have nearly the same occurrence of information concerning organisation information, related law/regulations, annual report, press release and publications, information of its staff members and online fundraising availability. These are required functions and 
information for non-profit organisations' websites as mentioned by Spigelman and Evans [27]. However, Table 2 shows that there were noticeable differences for some of the information displayed for the two nations. With regards to the donation usage, the SK sites showed more frequency (17) than the UK sites (7). More than half of the UK sites have job and volunteer demand sections compared to that of the SK sites. It is noteworthy that 12 out of the 20 SK sites presented the donators' list (donators' names and their contributions) so visitors can see how much donation has been made and by whom, whereas only $1 \mathrm{UK}$ site provided such a service. Out of 20 SK websites, 18 had real time update features or date compared with 7 for the UK sites. Moreover, 4 UK sites provided text only version, but this was not found in the SK websites at all.

\begin{tabular}{|l|c|c|}
\hline \multirow{2}{*}{ Variable } & \multicolumn{2}{|c|}{ Actual frequency } \\
\cline { 2 - 3 } & SK & UK \\
\hline \hline Job openings & 3 & 11 \\
\hline Volunteer demand & 7 & 11 \\
\hline Last update indicator & 18 & 7 \\
\hline What the donation is used for & 17 & 7 \\
\hline Donators' list & 12 & 1 \\
\hline Secure access information & 3 & 7 \\
\hline Text only version & 0 & 4 \\
\hline Links to other sites & 15 & 7 \\
\hline
\end{tabular}

Table 2. Information frequency by category on charity websites (20 from each, SK and UK).
To examine how designers use colours on the websites, we counted the number of times a colour was used on the homepage. Table 3 presents these results. Some of colours like light pink, yellow, light blue etc. that did not notably appear, have not been included in the table, but they were counted for the total size and the percentage of colours. It is somewhat surprising that there were no significant differences manifested in terms of colour usage for the two countries.

White is the predominant colour for background for both countries. With regard to total colour usage, the dominant colours for SK are white $(24 \%)$, grey $(21 \%)$, black $(19 \%)$ and blue $(10 \%)$, and for UK are white $(41 \%)$, black $(29 \%)$, blue $(16 \%)$ and grey $(14 \%)$. White is the most frequently used for both countries. Blue is the most frequently used for hyperlinks in both countries. For logos, black and blue are favoured colours for SK sites, while white, red and black are frequently observed on the UK sites.

Photos and symbols were categorised and examined for images. The map of each country was often found as a symbol of immediate national recognition. Photos of people's facial expression were frequently used for both countries, e.g. smiling and sad people.

The menu types favoured by SK and UK differ. Drop down menus that dynamically appear when the mouse is positioned over the menu are used on most SK sites whereas static menus are most frequently found for the UK sites. Top left is the most popular position for logos for both countries. In terms of the position of the donation menu, top middle is dominant for SK sites, but in the UK sites, top left, middle left

\begin{tabular}{|l|c|c|c|c|c|c|c|c|c|c|c|c|c|c|c|c|c|}
\hline \multicolumn{1}{|c|}{ Colour } & \multicolumn{2}{|c|}{ Red } & \multicolumn{2}{c|}{ Orange } & \multicolumn{2}{c|}{ Purple } & \multicolumn{2}{c|}{ Green } & \multicolumn{2}{c|}{ Blue } & \multicolumn{2}{c|}{ Grey } & \multicolumn{2}{c|}{ Black } & \multicolumn{2}{c|}{ White } \\
\hline \hline Nation & SK & UK & SK & UK & SK & UK & SK & UK & SK & UK & SK & UK & SK & UK & SK & UK \\
\hline Background & & & 1 & & & & 1 & & & & 1 & 1 & & & 15 & 16 \\
\hline Frame & 1 & & & & & 1 & & 1 & & 2 & 17 & 9 & & & 3 & 2 \\
\hline Hyper link & & 3 & & 1 & & 2 & 2 & 1 & 6 & 7 & 5 & & 2 & 2 & & 1 \\
\hline Logo & 2 & 6 & 3 & & 1 & 1 & 3 & 3 & 6 & 4 & 1 & & 10 & 5 & 3 & 7 \\
\hline Text & & & & 1 & & & 1 & 2 & 1 & 5 & 7 & 1 & 18 & 20 & 8 & 9 \\
\hline Total & 3 & 9 & 4 & 2 & 1 & 4 & 7 & 7 & 13 & 18 & 31 & 11 & 30 & 27 & 37 & 35 \\
\hline
\end{tabular}

Table 3. The number of websites on which the colour appears (only first page of the website was considered). 
and middle right are equally liked. The SK sites contained a higher usage of images on the homepage compared with the UK sites as shown in Table 4.

Overall, we have found that SK sites have more features allowing input from users than the UK sites (Table 5).

The use of sound, animation or streaming video differed significantly between the two countries. In fact, none of the UK sites used streaming video or sound while seven South Korean sites included such features. Only four of the UK sites used animation whereas as many as 18 out of $20 \mathrm{SK}$ sites used animation.

\begin{tabular}{|l|r|r|}
\hline Function & \multicolumn{1}{|c|}{ SK } & UK \\
\hline \hline Message board & 20 & 1 \\
\hline Online community & 7 & 0 \\
\hline Personalisation (Sign In) & 16 & 5 \\
\hline Online poll & 1 & 0 \\
\hline Email/location address & $16 / 18$ & $15 / 17$ \\
\hline
\end{tabular}

Table 5. User input.

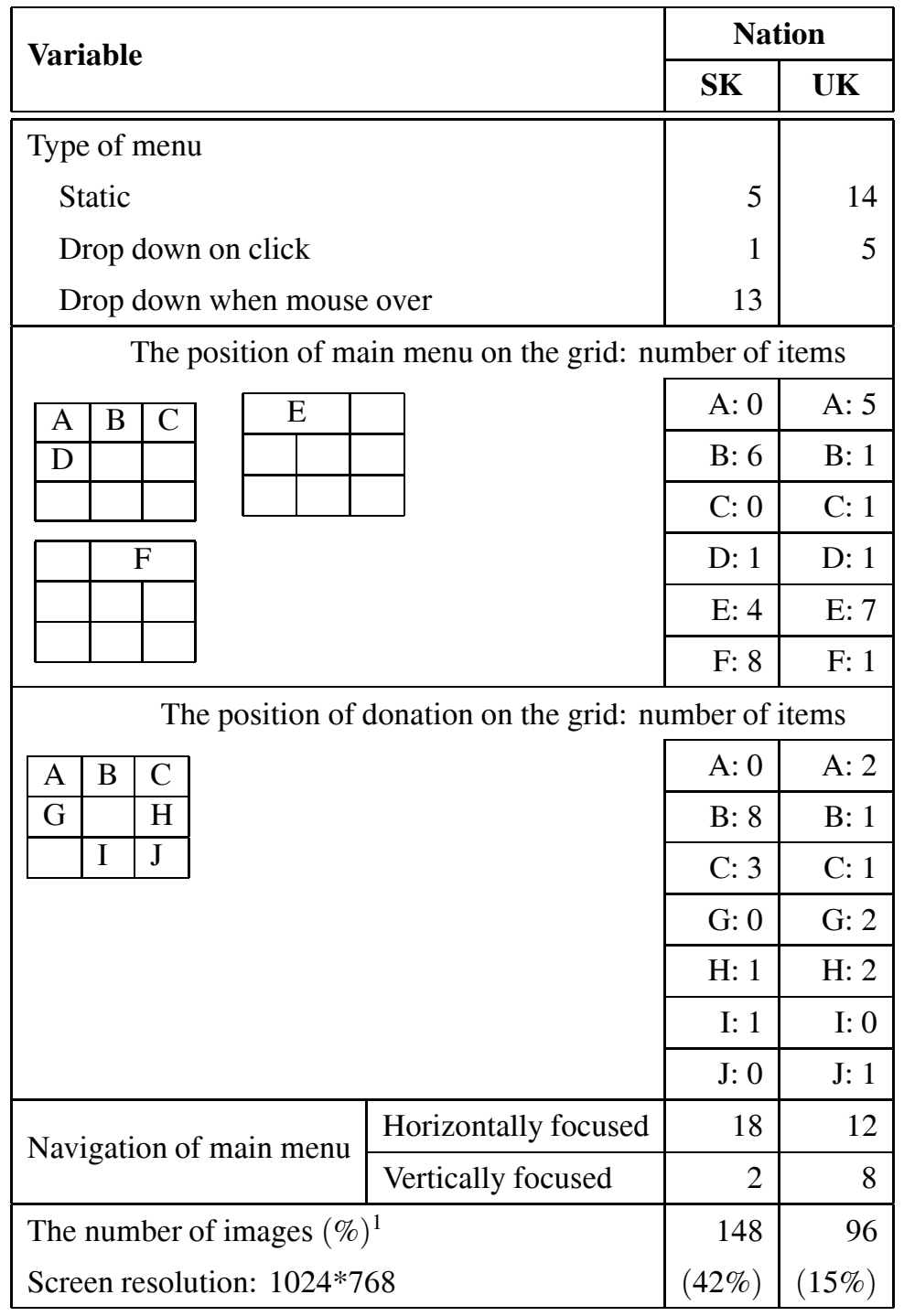

Table 4. Page layout characteristics.

\footnotetext{
${ }^{1}$ The Cool ruler tool (version 1.5) was used to measure the percentages of the images on the screen. By appearing on the screen, this tool is either horizontally or vertically adjustable and measures in inches, pixels, and centimetres.
} 


\section{Discussion and Conclusions}

No significant differences in the use of colour were found. This is somewhat surprising since some of the typical colour usage and preferences were not observed as expected. According to Boor and Russo [28], the meanings of colours have different associations in different cultures. For example, in Japan, white is a colour that implies death whereas in Egypt it indicates joy. Considering that white is the most frequently used background colour for both countries, as indeed is the case globally, this may indicate the trend of applying common standards in web design where readability and usability concerns override the other, less important ones, such as the common culturally established use of colour.

However, we observed noteworthy differences in the use of user input and multimedia. The South Korean web sites use multimedia and user input much more frequently than do the web sites in the United Kingdom. The more frequent occurrences of online communities and message boards on the SK sites can be considered to reflect the 'collectivist' type of a society where social values and group decision-making are nurtured. In contrast, in an 'individualist' society such as UK the individual freedom and personal decision-making are promoted, therefore there is no need for such facilities on the UK websites. Or, this clear preference is perhaps not due to differences in cultures, but are rather due to the more advanced technology infrastructure in South Korea which allows for rich communication such as animation, audio and video. SK's broadband penetration rate $(26.4 \%)$ was higher than the UK (19.4\%), according to the OECD Broadband statistics [29].

The far more explicit details published about donators and the use of donations on SK sites may be explained by SK's strong uncertainty avoidance culture where individuals try to avoid ambiguous situations and are looking for guidance.

\section{Conclusions}

Our research focuses on an investigation of web site design differences between two very different cultures (South Korea and United Kingdom) and tries to answer whether the observed differences in web design are due to the differences in culture between such societies. In order to identify such instances, we performed an empirical study comparing design features for charity websites of South Korea and United Kingdom. Our findings provide some evidence that can be used to support our hypothesis that design preferences are somewhat different across cultures. The main differences appear to be in much more liberal use of sound, video and animation in South Korean sites than in the United Kingdom web sites. However, it is difficult to attribute these differences solely to culture. The study was conducted on the data from 2007 when the effect of technology infrastructure may have been far greater than that of culture. It would be interesting to conduct a similar study now, when the previous technological differences are no longer so great, if at all.

The more culturally significant differences observed might be the more frequent occurrences of online communities and message boards on the SK sites as these phenomena can be considered to reflect the 'collectivist' type of a society where social values and group decision-making are nurtured. Also, SK sites provide much more explicit details about donators and donations than the UK sites. This may be explained by its strong uncertainty avoidance culture where individuals try to avoid ambiguous situations and are looking for what others did to possibly guide their own behaviour. In contrast in 'individualist' society such as UK where the individual freedom and personal decision-making are highly valued, information on behaviour of others may not be necessary in guiding their own behaviour.

\section{References}

[1] Miniwatts Marketing GROUP. Internet growth and stats. 2000-2010. Miniwatts Marketing Group. http://www. internetworldstats.com.

[2] E. T. HALl, M. R. HALL, Understanding Cultural Differences: Germans, French and Americans. Yarmouth, Maine, Intercultural Press, 1990.

[3] V. EVERS, Cultural Aspects of User Interface Understanding; An Empirical Evaluation of an E-Learning Website by International User Groups. London, The Open University, 2001. 
[4] G. Hofstede, Culture's consequences: International differences in work-related values. Beverly Hills, CA, Sage, 1980.

[5] N. T. FEATHER. Values, valences, and choice: the influence of values on the perceived attractiveness and choice of alternatives. Journal of personality and social psychology, 68(6), 1135-51, 1995.

[6] D. K. Tse, R. W. BelK, N. Zhou. Becoming a Consumer Society: A Longitudinal and Cross-cultural Content Analysis of Print Ads from Hong Kong, the People's Republic of China, and Taiwan. The Journal of Consumer Research, 15(4), 457-72, 1989.

[7] R. G. D'ANDRADE, Schemas and motivation. Cambridge, UK, Cambridge University Press, 1992.

[8] G. HofstedE, Cultures and Organisations: Software of the mind: Intercultural Coorperation and its Importance for Survival. New York, McGraw Hill, 1991.

[9] W. BARBER, A. BADRE, Culturability: The Merging of Culture and Usability. Proceedings of the Fourth Conference on Human Factors and the Web, NJ, 1998.

[10] H. Sun, Building a Culturally Competent Web Site: An Exploratory Study of Cultural Markers in Multilingual Web Design. Proceedings of SIGDOC, Sante Fe, New Mexico, USA, p. 95-102, 2001.

[11] A. BADRE, S. LASKOwSKI, The Cultural Context of Web Genres: Content vs. Style. Proceedings of the 7th Conference on Human Factors and the Web, Wisconsin, 2001.

[12] B.-M. YU, S.-Z. RoH, The effects of menu design on information-seeking performance and user's attitude on the World Wide Web. Journal of the American Society for Information Science and Technology, 53(11), 923-33, 2002.

[13] A. Marcus, E. W. Gould, Cultural Dimensions and Global Web User-interface Design: What? So What? Now What? Proceedings of the 6th Conference on Human Factors and the Web, Austin, Texas, 2000 .

[14] C. B. DiAnNe CYR, JoE ILSEVER. Innovation, management \& strategy: Design and e-loyalty across cultures in electronic commerce. Proceedings of the 6th International Conference on Electronic Commerce, Delft, The Netherlands, March 2004.

[15] P. Y. K. Chau, M. Cole, A. P. Massey, M. Montoya-Weiss, R. M. O'KeEFE, Cultural differences in the online behavior of consumers. Communications of the ACM, 45(10), 138-43, 2002.

[16] D. Luna, L. A. Peracchio, M. D. DE Juan. CrossCultural and Cognitive Aspects of Web Site Navigation. Journal of the Academy of Marketing Science, 30(4), 397-410, 2002.

[17] S. J. Simon. The Impact of Culture and Gender on Web Sites: An Empirical Study. Data Base for Advances in Information Systems, 32(1), 18-37, 2001.
[18] W. Zhao, B. L. Massey, J. Murphy, L. Fang, Cultural Dimensions of Website Design and Content. Prometheus, 21(1), 75-84, 2003.

[19] K. W. OH, C. H. CHO, J. D. LeCKenBy, A Comparative Analysis of Korean and U.S. Web Advertising. Proceedings of the 1999 Conference of the American Academy of Advertising, Albuquerque, New Mexico, p. 73-86, 1999.

[20] N. Singh, H. ZHAO, X. Hu, Analyzing the cultural content of web sites: A cross-national comparision of China, India, Japan, and US. International Marketing Review, 22(2), 129-46, 2005.

[21] C. H. Cho, H. J. Cheon, Cross-cultural Comparisons of Interactivity on Corporate Web Sites: The United States, the United Kingdom, Japan, and South Korea. Journal of Advertising, 34(2), 99$115,2005$.

[22] J. HU, K. SHIMA, R. OEHLMANN, J. ZHAO, Y. TAKEMURA, K.-I. MATSUMOTO, An empirical study of audience impressions of B2C web pages in Japan, China and the UK. Electronic Commerce Research and Applications, 3(2), 176-89, 2004.

[23] A. Kralisch, B. Berendt, Cultural determinants of search behaviour on websites. Proceedings of the IWIPS 2004 Conference on Culture, Trust, and Design Innovation, Vancouver, Canada, 2004.

[24] R. E. NISBETT, The Geography of Thought: how Asians and Westerners think differently and why. New York, Free Press, 2003.

[25] Y. Hong, C. CHIU, Toward a paradigm shift: From cross-cultural differences in social cognition to social-cognitive mediation of cultural differences. Social Cognition, 19(3), 181-96, 2001.

[26] A. Faiola, S. A. Matei. Cultural Cognitive Style and Web Design: Beyond a Behavioral Inquiry into Computer-mediated Communication. Journal of Computer-mediated Communication, 11(1), 2005. http://jcmc.indiana.edu/vol11/issue1/ faiola.html [10/02/2007]

[27] A. Spigelman, E. Evans, Virtual Promise - From Rhetoric to Reality - A report on charities' use of the internet between 2000-2004. nfpSynergy. London, 2004.

[28] P. Russo, S. BooR, How fluent is your interface? Designing for international users. Proceedings of the SIGCHI Conference on Human Factors in Computing Systems, Amsterdam, The Netherlands, 1993.

[29] OECD. OECD Broadband statistics. 13 October 2006. http: //www . oecd.org/document/9/ 0, 2340, en_2649_34223_37529673_1_1_1_ 1,00.html, [17/03/2007]. 
Received: June, 2009

Accepted: April, 2010

Contact addresses:

Inhwa Kim

People and Interactivity Research Centre

School of Information Systems,

Computing and Mathematics

Brunel University, West London

Uxbridge, Middlesex UB8 3PH

United Kingdom

e-mail: Inhwa.Kim@brunel.ac.uk

Jasna Kuljis

People and Interactivity Research Centre

School of Information Systems,

Computing and Mathematics

Brunel University, West London

Uxbridge, Middlesex UB8 3PH

United Kingdom

e-mail: Jasna.Kuljis@brunel.ac.uk

INHWA KIM is a PhD candidate in the School of Information Systems, Computing and Mathematics at the Brunel University, UK. She works as a full-time employee at Samsung SDS Europe in UK. Her research interests are in cross-cultural research and design, user research, website design, web 2.0 technology and persuasive technology.

JASNA KULJIS is a Professor and Head of Department of Information Systems and Computing (DISC) at Brunel University, London, UK. Her research interests in $\mathrm{HCI}$ include simulation modelling and healthcare applications, and she has published widely in the HCI and Operational Research literature. Jasna is also Director of the Brunel University Research Centre called People and Interactivity (PANDI). Jasna first attended the second ITI conference in 1980 (the conference was then called International Symposium Computer at University) with a paper in Croatian (it was then a choice between Croatian and English): Kuljis, J. and M.A. Vouk. Comparative analysis of some routines for numerical integration of the Fermi integral. She has attended most of the ITI conferences since then - in total more than 20 conferences. Since 2004 she has been a conference vice-chair for the topic Human Computer Interaction. 